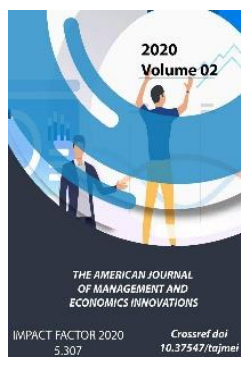

Copyright: Original content from this work may be used under the terms of the creative commons attributes 4.0 licence.

\section{The Nature Of Firm's Internal Environment Capabilities And Competencies Dynamics Evaluation: Feasible Strategy Crafting Imperatives}

John E. Chikwe

Ph.D, Department Of Management University Of Port Harcourt Nigeria

Chris Sam Biriowu

Ph.D, Department Of Management Rivers State University Port Harcourt, Nigeria

\title{
ABSTRACT
}

The study strategically evaluated the nature of firm's internal environment capabilities and competencies dynamics that will ensure feasible strategy crafting. The understanding and analysis of the challenges posed in the internal environment helps strategists to make strategic decisions relating to the resources, capabilities and core competencies since they are non routine. In order to facilitate the development and effective usage of core competencies, managers/strategists are advised to have courage, self-confidence, integrity, the capacity to deal with uncertainty and complexity, and a willingness to hold people accountable for their work, as well as their being accountable themselves. This should be necessitated because the competitive advantage and firm's performance are often strongly related to the resources firms hold and how they are managed. This is found to be so, since human beings are strategic critical resource that produces innovation, develops policies and strategies, and firm's competitive advantage enhancement. The study further explored some related perspectives of valuable capabilities, personnel and organizational competencies, resources tangibility and intangibility, as well as competitive advantage sustainability criteria that will guide feasible strategy crafting. The study recommends amongst others, that organization managers should as a matter of necessity, monitor and evaluate the internal environment capabilities and competencies in order to have fit with that of external resources dynamics to enhance feasible strategy crafting.

\section{KEYWORDS}

Environment; Capabilities; Competencies; Strategy Crafting Imperatives; Organizational dynamics; Resources. 


\section{INTRODUCTION}

The internal environment of an organization consists of the variables that are within the organization such as strengths, weaknesses, structure, culture, resources, key functions within the enterprise and organization's climate. As we are today witnessing from the happenings in the business world environment, several factors in the global economy, including the rapid development of the internet's technology capabilities, some aspects of globalization in general have made it increasingly difficult for firms to develop competitive advantage that can be sustained for an envisaged period of time. In these instances however, firms try to create sustained competitive advantages by continually producing innovative products and services. Firms should not only have the correct structure, but also the appropriate resources to build innovation capabilities. This as suggested is so because, the probability of developing a sustainable advantage increases when the firms use their own unique resources, capabilities, and core competencies on which to base and implement their strategies. Business strategy is always intertwined with capabilities (Chikwe, 2018).

It is also asserted that the competitive advantages and differences strategists create in firm performance are often strongly related to the resources firms hold and how they are managed (Dutta, Zbaracki, and Bergen, 2003; and Knott, 2003). Resources as we know are the foundation for strategy crafting and execution, and the unique bundles of resources generate competitive advantages that lead to wealth creation (Brush, Green, and Hart, 2001). In order to identify and successfully use their resources over time, it is worthy to remark that, those leading firms should think constantly about how to manage them in order to increase the value for customers (Makadok, 2001; Douglas and Rymaw, 2003). A critical analysis of these assertions indicate that, firms achieve strategic competitiveness and could earn above-average returns when their unique core competencies are effectively acquired, bundled, and leveraged to take advantage of opportunities in the external environment.

Since organizational culture influences the way companies conduct its business in addition to helping to regulate and control employee's behaviour, it can be a source of competitive advantage (Barney, 1986). In view of this, a company can develop core competencies in aspects of both the capabilities it possesses and the way the capabilities are leveraged by strategies to produce the desired outcomes (Hitt, Hoskisson, and Ireland, 2007).

Human beings are strategic critical resource for producing innovation as well as the gaining of a competitive advantage. Nevertheless, even if human beings are not as critical in some industries, they are in effect necessary for the development of companies policies and strategies. Relatedly, in view of the importance of talented employees, such has necessitated the development of global labour market. This actually makes it that, wherever talent goes to be associated with innovation, creativity, and economic growth are ensured as relatedly opined by Florida (2005). However, time, the benefits of any company's value-creating strategy can be duplicated by its competitors, which implies that, all competitive advantages have a limited life as similarly argued by Autio, Sapienza, and Almeida, (2000) and Shamsie, (2003).

Succinctly, the analysis of the firm's internal environment will require the evaluators to examine the company's portfolio of resources as well as the bundles of heterogeneous resources and capabilities that managers have created. This aspect actually suggest that individual companies in essence, possess at least some bundles of resources and capabilities that other organization do not, and 
specifically, not in the same combination. Resources as we know are the source of capabilities, and some of which may eventually lead to the development of a firm's core competencies or its competitive advantages. In view of this, we should note that the understanding of how to leverage the firm's unique bundle of resources and capabilities is a key outcome which strategist may seek when analyzing the internal environment.

\section{Theoretical Framework and Review of Relevant Literature}

\section{Analysis of the Internal Environment Challenges}

In understanding and analyzing the challenges posed in the internal environment, we should also understand that the strategic decisions managers make relating to the resources, capabilities, and core competencies are non routine as Hough and White (2003), have relatedly pointed out. Those strategic decisions also have ethical implications (Robertson and Crittenden, 2003), and significantly influence the firm's ability to earn above-average returns (Christensen and Raynor, 2003). In making these strategic decisions which involves identifying, developing, deploying and protecting resources, capabilities, and core competencies may however, appear to be relatively easy, but in essence, challenging and difficult. In order to surmount these problems, it is of necessity very essential to identify the firm's competence before important strategic decisions can be made, including those related to entering or exiting markets, investing in new technologies, building new or additional manufacturing capability, or forming strategic partnerships (Hitt, et al, 2007).

Nutt (2002) is of the opinion that, the challenge and difficulty of making effective decisions are implied by preliminary evidence, and suggesting that one-half of organizational decisions fail. This is so since mistakes are sometimes made as the firm analyzes its internal environment. For instance, managers might identify capabilities as core competencies that do not create a competitive advantage, and when such error happens, decision makers are advised to have the confidence to admit it and effect corrective actions. Nevertheless, researches suggest that, a firm can still grow through well-intended errors, and the learning generated by making and correcting mistakes can be important to the creation of new competitive advantage (Gavetti and Levinthal, 2000; West III and DeCastro, 2001).

In order to facilitate the developing and using core competencies, we suggest that managers must have courage, self-confidence, integrity, the capacity to deal with uncertainty and complexity, and a willingness to hold people accountable for their work, and on the other hand, they should also be held accountable themselves. In sum, difficult managerial decisions relating to resources, capabilities, and core competencies are characterized by three conditions: uncertainty, complexity, and intra-organizational conflict as relatedly argued by Amit and Schoemaker (1993) in figure 2 .

We understand that managers may face uncertainty in the areas of new proprietary technologies, rapidly changing economic and political trends, transformations in social values, and shifts in customer demands, as relatedly opined by Hoskisson and Busenitz (2002). Similarly, Fiol and O'Connor (2003) expressed that, environment increases the complexity and range of issues to examine when studying the internal environment. This as noted, is so because, biases concerning how to cope with uncertainty may affect decisions in terms of the resources and capabilities that will become the foundation of the firm's competitive advantage. In the areas of intraorganizational conflicts, such as pointed out, issues may surface or come up when decisions are made in terms of the core 
competencies to nurture as well as how to nurture them.

\section{Organizational Resources, Capabilities and Core Competencies}

Organizational resources, capabilities, and core competencies are the basics that provide the foundation of competitive advantage. In specific, resources are the fundamental sou mrces of a firm's capabilities, and are bundled to create organizational capabilities. Relatedly, capabilities in turn, are the source of firm's core competencies, which are also the basis of competitive advantage. Organizations have core competencies when they can exceedingly do well on specifications or specific areas. However, when such competencies capabilities are superior to that of the competitors, they are therefore called distinctive competencies as earlier explained. Organizational resources should be evaluated as to ascertain if they are internal strategic factors. This means those particular strengths and weaknesses that will enhance the determination of the firm's future. This can however be done by comparing measures of these resources with measures of:

- The company's past performance;

- The company's key competitors;

- The industry as a whole.

For example, the evaluation of a resource such as financial situation of a firm, to determine if success is significantly different from the firm's own past, its key competitors, or the industry average, and if positive, such resources is likely going to be a strategic factor and should be considered in strategic decisions (Wheelen and Hunger, 2004).

The idea of core competence was described in 1990 by Hamel and Prahalad. The idea emphasize that each organization has some capability in which it excels and that the business should focus on opportunities in that area, and letting others to go or outsourcing them. Core competency is difficult to duplicate, since it involves the skills and coordination of people across a variety of functional areas or processes used to deliver value to customers. Core competence is a branch of strategy called the resource-based view (RBV) of the firm. This, in essence, postulates that, if activities are strategic as indicated by the value chain, then the organization's capabilities and ability to learn or adapt are also strategic (Ghemawat, 2002).

\section{Organizational Resources}

Organization's resource is an asset, competency, process, skill, or knowledge controlled by the corporation. A resource is a strength to the firm if it provides the organization with a competitive advantage. This implies that such resource should be something the firm does or has the potential to do specifically well relative to the abilities of existing or potential competitors. In general, organizational resources cover a spectrum of individual, socio-cultural, materials, structures and organizational phenomena. In specific, a resource alone do not yield a competitive advantage (Chi, 1994; Deeds, De Carolis and Coombs, 2000); rather, a competitive advantage is generally based on the unique bundling of several resources (Berman, Down and Hill, 2002; Simon, Hitt and Ireland, 2007). For instance, a firm can combine service and distribution resources to enhance its competitive advantages.

Barney (1997), in his VRIO (Value, Resources, Imitability, Organization) acronym framework of analysis, made a proposition of four questions for the purpose of evaluating each of a firm's key resources thus:

- Value: Does it provide competitive advantage? If "yes" for a particular resource, this means that the resource is a strength and has a distinctive competence.

- Rareness: Do other competitors possess it? 
Organization: Is the firm organized to exploit the resource?

- Imitability: Is it costly for others to imitate? Imitability is the rate at which a firm's underlying resources and capabilities (core competencies) can be duplicated by others. Wheelen and Hunger (2004) argued that, it is relatively easy to learn and imitate another company's core competence, or capability if it comes from explicit knowledge. This implies the knowledge that can be easily articulated and communicated by competitive intelligence activities. In contrast, tacit knowledge is the knowledge that is not easily communicated as it is deeply rooted in employee experience or in a company's culture (Polanyi, 1966). It is further noted that tacit knowledge is more valuable and more likely to lead to a sustainable competitive advantage than is explicit knowledge, as tacit knowledge is much harder for competitors to imitate. The imitation difficulty in tacit knowledge is due to the fact that the knowledge may be complex and combined with other types of knowledge in an unclear fashion, and in competency (Bierly, 1999).

\section{Usage of Resources to Gain Competitive Advantage}

In exploring how to use resources to gain competitive advantage, Grant (1991) propounded the proposition that a company's sustained competitive advantage is primarily determined by its resources endowments, and further suggested a five-step, resource-based approach to strategy analysis.

- Identification and classification of the firm's resources in terms of strengths and weaknesses.
- The combination of the firm's resources into specific capability. Corporate capabilities (often called core competencies) are the things that a firm can do exceedingly well and when these capabilities or core competencies are superior to those of competitors, they could therefore be called distinctive competencies.

- The appraisal of the profit potential of these resources and capabilities in terms of their inherent potential for sustainable competitive advantage, and the ability to harvest the profits resulting from the use of these resources and capabilities.

- The selection of the strategy that best exploits the firm's resources and capabilities relative to external opportunities.

- The identification of resource gaps and investment in upgrading weaknesses.

\section{Tangibility of Resources}

Some firms resources are tangible while some other are intangible. Hitt, et al (2007) defined tangible resources as assets that can be seen and quantified. For example, the production equipment, manufacturing plants, and formal reporting structures are classified under tangible resources.

One the other hand, intangible resources are assets that are deeply rooted in the company's history and have accumulated over time. For the fact that intangible resources are embedded in unique patterns of routines, they are relatively difficult for competitors to analyze and imitate. Some examples of intangible resources include: knowledge, trust between managers and employees, organizational climate, managerial capabilities, organizational routines (i.e. the unique ways people work together), scientific skills and capabilities, the capacity for innovation, organizational image, goodwill and reputation for its goods and services and how it interacts 
with people (such as employees, customers, and suppliers).

\section{Types of Tangible Resources}

There are four-basic types of tangible resources as opined by Barney (1991), and these are:

1. Financial resources

- $\quad$ The firm's borrowing capacity

- The firm's ability to generate internal funds

2. Organizational resources

- The firm's formal reporting structure and its formal planning, controlling and coordinating systems

3. Physical resources

- Sophistication and location of a firm's plant structure, and equipment

- Access to raw materials

4. Technological Resources

- Stock of technology, such as patents, trademarks, copyrights, and trade secrets.

An organization's borrowing capacity and the status of its plant and equipment confirm its tangibility visible. As observed, the value of many tangible resources can be established through financial statements, but these statements as noted do not account for the value of all of a company's assets, due to the fact that they disregard some intangible resources as relatedly noted by Lubit (2001), as well as Subramani and Venkataraman (2003).

As a result of these, each of the company's sources of competitive advantage may not in specific, be fully reflected on corporate financial statements. It is also interesting to note that the constraining nature of the value of tangible resources makes them difficult to leverage. This is so because of the envisaged difficulty in deriving additional business or value from the tangible resources. For example, a motor car is a tangible resource but it is difficult to use the same car on ten different routes at the same time, and such goes to the financial investment one has made in the motor car. However, irrespective of the fact that production assets are tangible, many processes that will use the assets are intangible. In view of these, we should know that, the learning and potential proprietary processes associated with a tangible resources relating to manufacturing equipment, can in essence have unique tangible attributes, such as quality control processes, unique manufacturing processes, and technology that develop over time and create competitive advantage (Schroeder, Bates, and Juntilla, 2002; Song, Droge, Hanvanich, and Calatone, 2005).

\section{Types of Intangible (Unobservable) Resources}

The three basic types of organization's intangible resources as expressed by Hall (1992) are:

\section{Human Resources}

- Knowledge

- Trust

- Managerial capabilities

- Organizational routines

2. Innovation Resources

- Ideas

- Scientific capabilities

- Capacity to innovate

- Technological innovation

- Process innovation

- Product innovation

3. Reputational Resources (Goodwill)

- Reputation with customers

- Brand name

- Perceptions of product quality, durability, and reliability

- Reputation with suppliers 
- Efficient, effective, supportive, and mutually beneficial interactions and relationships.

- Organizational image.

In placing tangible resources and intangible resources on a comparative analysis, it has been argued that intangible resources are a superior and more potent source of core competencies (Hitt and Ireland, 2002). It is also factual that in the global economy, the success of a company lies more in its intellectual and moreover, the capacity to manage human intellect and convert it into useful products and services is fast becoming the critical executive skill of the age (Quinn, Anderson and Finkelstein, 1996). However, even though the measurement of intangible assets such as knowledge may pose some difficulties, research has it that, the value of intangible assets is growing relative to that of tangible assets (King and Zeithaml, 2003; Tallman, Jenkins, Henry and Pinch, 2004).

In view of the fact that intangible resources are less visible and more difficult for competitors to comprehend, understand, purchase, imitate, or substitute for, companies mostly prefer to rely on them than on tangible resources as the foundation for their capabilities and core competencies. In essence, the more unobservable (i.e. intangible) a resource is, the more sustainable the competitive advantage by which it is based on should be (Funk, 2003). Intangible resources also have the benefit of being leveraged, unlike tangible resources. In intangible resources, if the network of user is larger, there will be greater benefit to each party. This for instance implies that, sharing knowledge which is an intangible resource among employees will not diminish its value for any person. Also if two persons are sharing their individualized knowledge, they can be leveraged to create additional knowledge that may be new to each and such can contribute to performance improvements for the firm (Ireland, Hitt, and Vaidyanath, 2002).
In terms of reputation, it is noted that, a valuecreating reputation is a product of distilled years of superior marketplace competence as perceived by stakeholders and such is earned through the firm's actions, as well as words (Deephouse, 2003). The reputation of the firm actually indicates the level of awareness a firm has been able to develop among stakeholders, and the degree to which the firm is held in high esteem. For instance, a well-known and highly valued brand name is an application of reputation as a strategic source for competitive advantage as similarly opined by Berthon, Holbrook, and Hulbert, (2003). Relatedly, it is observed that regular commitment to innovation and associated aggressive advertising help to facilitate the firms' efforts to take advantage of the reputation associated with their brands (Blasberg and Vishwanath, 2003).

\section{Nature of Organizational Capabilities Dynamics}

Organizational capabilities have been somewhat treated elsewhere in this paper, but our emphasis under this section is more on the nature of the dynamics. However, organizational capabilities is said to exist when resources have been purposely and strategically integrated to achieve a specific task or set of tasks. These tasks range from human resource selection to product marketing as well as research and development activities (Dutta, Narasimhan, and Rajiu, 2005; Simon, Hitt, and Ireland, 2007). The building of competitive advantages and capabilities are often based on developing, carrying, and exchanging information and knowledge through the firm's human capital. Client-specific capabilities often develop from repeated interactions with clients and the learning about their needs that occur (Ethiraj, Kale, Krishnan, and Singh, 2005). In view of this, it is therefore observed that capabilities often evolve and develop over time (Jacobides and Winter, 2005). Deeds (2003) points out 
that global business leaders are increasingly supporting the view that the knowledge possessed by human capital is among the most significant of an organization's capabilities and may ultimately be at the root of all competitive advantages.

However, research has it that there exists a relationship between capabilities developed in particular functional areas and the firm's financial performance at both the corporate and business-unit levels, and such suggests the need to develop capabilities at both levels (Snow and Hrebiniak, 1980; Hitt, Ireland, and Palia, 1982).

\section{Managerial Competencies}

Having known the various levels of management (top, middle and lower levels) and what managers do or their functions (planning, organizing, directing and controlling), one may still be wondering in specific, what it takes to be an effective or even a great manager. In view of these, it becomes pertinent for us to look more closely at the expected competencies that managers may need in order to craft and execute strategies effectively. A competency as defined by McCall (1998) is a combination of knowledge, skills, behaviours, and attitudes that contribute to personal effectiveness.

Managerial competencies are therefore sets of knowledge, skills, behaviours, and attitudes that a person needs to be effective in a wide range of positions and various types of organizations (Hellriegel, Jackson, and Slocum, 2005). The six key managerial competencies dimensions or measures managers need to be effective are as variously exemplified (Greenboro, 1999; Goldstein, Yusko, Nicolopoulos, 2001; and Hellriegel, et al, 2005; Chikwe and Biriowu, 2019).

- Communication competency

- $\quad$ Planning and administration competency

- $\quad$ Teamwork competency
- $\quad$ Strategic action competency

- Global awareness competency

- Self-management competency

\section{Competitive Advantage Sustainability Criteria}

The fact that a company would be able to use its resources and capabilities for the development of a competitive advantage does not just mean that it would be able to sustain it. Usually, an organization can maintain or sustain its competitive advantage within a certain specific period, because of rival company's imitating and undermining such advantage. To achieve a sustained competitive advantage, a company must of necessity, strive to:

i. Ensure that competitors do not succeed in their imitation or duplication strategies.

ii. Continually try to adapt to changes in the external environment trends and events, as well as that of internal environment capabilities, resources and competencies;

iii. Seriously get involved in the effective formulation, implementation, and the evaluation of strategies that strategically capitalize upon those envisaged factors.

\section{CONCLUSIONS}

Significantly, this evaluative paper has clearly demonstrated and provided to a great extent, a clear and strategic understanding on the nature of internal environment capabilities and competencies dynamics evaluation. The results of these indicate that, it is necessary to understand that the strategic decisions mangers or strategists execute relating to the resources, core competencies and capabilities are strategically non routine, have ethical implications, and there should be every need to identify the organization's competencies before crafting and executing strategic 
decisions. The implications of these encapsulate the fact that, resources are strategic fundamental sources of an organization's capabilities. These are also bundles that create organizational capabilities, which inturn metamorphose to core and distinctive competencies, leading to competitive advantage. Virtually, in every business-oriented organization, the survival and even continuous existence may be difficult in the absence of relevant evaluation of the internal environment capabilities and strategic competencies dynamics. It is observed that the internal environment capabilities and competencies in many business organizations globally and in Nigeria in specific, are becoming increasingly vulnerable hence the need to evaluate the dynamics cannot be overemphasized.

\section{Recommendations}

The study recommends an increasing and periodic attention on the internal environment vulnerabilities minimization. It also recommends that organization managers should as a matter of necessity, monitor and evaluate the internal environment capabilities and competencies in order to have effective fit with that of the external environment resources dynamics as to achieve feasible strategy crafting.

\section{REFERENCES}

1. Autio, E., Sapienza, H.J., \& Almeida, J.G. (2000). Effects of age at entry, knowledge intensity, and imitability on international growth, Academy of Management Journal, 43:909-924.

2. Barney, J.B. (1986). Organizational Culture: Can it be a source of sustained competitive advantage? Academy of Management Review, 11:656-665.
3. Barney, J.B. (1991). Firm resources and sustained competitive advantage, Journal of Management, 17:99-120.

4. Barney, J.B. (1997). Gaining and Sustaining Competitive Advantage. Reading, M.A.: Addison-Wesley, 145164.

5. Berman, S.L., Down, J. and Hill, C.W.L. (2002). Tacit knowledge as a source of competitive advantage in the National Basketball Association, Academy of Management Journal, 45: 13-31.

6. Berthon, P., Holbrook, M.B. \& Hulbert, J.M. (2003). Understanding and managing the brand space, MIT Sloan Management Review, 44(2): 44(2):4954 .

7. Bierly, P.E. (1999). Development of a Generic Knowledge Strategy Typology. Journal of Business Strategies. Springs, 3.

8. Brush, C.G., Green, P.G., \& Hart, M.M. (2001). Initial idea to unique advantage: the entrepreneurial challenge of constructing a resource base, Academic of Management Executive, 15(1): 64-78.

9. Chi, T. (1994). Trading in strategic resource: necessary conditions, transaction cost problem, and choice of exchange structure; Strategic Management Journal, 15: 271-290.

10. Chikwe, J.E. (n.d.). Business Policy and Strategic Management Dynamics, Text and Cases, (in Press).

11. Chikwe, J.E. (2018). Fundamental Concept of Strategy Development: A Critical Examination. Global Journal of Business Management, 12(1), 125-139, June, New Delhi, India.

12. Chikwe, J.E. \& Biriowu, C.S. (2019). Managerial Competencies and Organizational Innovativeness: Evidence from selected. Small and Medium Enterprises (SMEs) in Port Harcourt, Nigeria. International Journal of Research in Business Management (IMPACT: IJRBM), 7(6), 17-30, June. 
13. Christensen, C.M. \& Raynor, W.F. (2003). Why hard-rosed executives should care about management theory. Harvard Business Review.

14. Deeds, D.L., De Carolis, D., \& Combs, J. (2000). Dynamic capabilities and new product development in hightechnology ventures: An empirical analysis of new technology firms. Journal of Business Ventures, 15: 211-229.

15. Deeds, D.L. (2003). Alternative strategies for acquiring knowledge; in Jackson, S.E., Hitt, M.A and Denisi, A.S. (eds); Managing Knowledge for Sustained Competitive Advantage, San Francisco: Jossy-Bass, 37-63.

16. Deephouse, D.L. (2003). Media reputation as a strategic resource: an integration of mass communication and resource-based theories, Journal of Management, 26: 1091-1112.

17. Douglas, J.J; \& Ryman, J.A. (2003). Understanding competitive advantage in the general hospital industry: Evaluating strategic competencies: Strategic Management Journal, 24: 3347.

18. Dutta, S., Navasimhau, O. \& Rajiv, S. (2005). Conceptualizing and measuring capabilities: Methodology and empirical application, Strategic Management Journal, 26:277-285.

19. Dutta, S., Zbaracki, M.J., \& Bergen, M. (2003). Pricing process as a capability: A resource-based perspective; Strategic Management Journal, 24:615630.

20. Ethiraj, S.K., Kale, P., Krishnan, M.S., \& Singh, J.V. (2005). Where do capabilities come from and do they mater? A Study of the software services industry, Strategic Management Journal, 26:25-45.

21. Fiol, C.M. \& O'Connor, E.J. (2003). Waking up! Mindfulness in the face of Bandwagous; General Management, 20(3): 76-90 Spring.
22. Florida, R. (2005). The Flight of the Creative Class; New York: Harper Business.

23. Funk, K, (2003). Sustainability and performance, MIT Sloan Management Review, 44(2):65-70.

24. Gavetti, G. \& Levinthal, D. (2000). Looking forward and looking backward: Cognitive and experimental research, Administrative Science Quarterly, 45: 113-137.

25. Ghemawat, P. (2002). Competition and business strategy in historical perspective, Harvard Business Review.

26. Goldtein, H.W., Yusko, K.P.; \& Nicolopoulos, V. (2001). Exploring black-white subgroup differences of managerial competences, Personnel Psychology, 54:782-808.

27. Grant, R.M. (1991). Contemporary Strategy Analysis. Cambridge, UK: Blackwell Business.

28. Greenboro, N.C. (1999). Centive for Creative Leadership, Personnel Psychology, 54:782-808.

29. Hall, R. (1992). The strategic analysis of intangible resources; Strategic Management Journal., 13: 136-139.

30. Hamel, G. \& Prahalad, C.K. (1990). The core competence of the corporation. Harvard Business Review. May-June.

31. Hellriegel, D., Jackson, S.E.; \& Slocum, J.W. (2005). Management: A competency-based approach ( $10^{\text {th }}$ ed.), Mason, Ohio: Thomson SouthWestern.

32. Hitt, M.A. \& Ireland, R.D. (2002). The essence of strategic leadership: Managing human and social capital; Journal of Leadership and Organization Studies, 9(1):3-14.

33. Hitt, M.A., Hoskisson, R.E., \& Ireland, R.D. (2007). Management of Strategy, Concepts and Cases; USA: Thompson South-Western Higher Education.

34. Hitt, M.A., Ireland, R.D. and Palia, K.A. (1982). Industrial firms' grand strategy 
and functional importance, Academy of Management Journal, 25:265-298.

35. Hoskisson, R.E. \& Busenitz, L.W. (2002). Market uncertainty and learning distance in entrepreneurship entry mode choice. Oxford, UK: Blackwall Publishers, 151-172.

36. Hough, J.R. \& White, M.A. (2003). Environment dynamism and strategic decision-making rationality: An examination at the decision level; Strategic Management Journal, 24: 385392.

37. Ireland, R.D., Hitt M.A \& Vaidyanath (2002). Managing strategic alliances to achieve a competitive advantage, Journal of Mangement, 28:416-446.

38. Jacobides, M.G. \& Winter, S.G. (2005). The co-evolution of capabilities and transaction costs: Explaining the institutional structure of production, Strategic Management Journal, 26:395413.

39. King, A.W. \& Zeithaml, C.P. (2001). Competence and Firm's performance: Examining the critical ambiguity paradox, Strategic Management Journal, 24: 763-772.

40. Knott, A.M. (2003). Persistent heterogenesity and sustainable innovation: Strategic Management Journal, 24:687-705.

41. Lubit, R. (2001). Tacit knowledge and knowledge management: The keys to sustainable competitive advantage; Organizational Dynamics, 29(3):164-178.

42. Makadok, R. (2001). Toward a synthesis of the resource-based and dynamiccapability views of rent creation; Strategic Management Journal, 22:387401.

43. McCall, M.W. (1998). High fliers: Developing the Next Generation of Leaders, Boston: Harvard Business School Press.

44. Nutt, P.C. (2002). Why decisions fail; San-Francisco: Berrett-Koeller Pub.
45. Polanyi, M. (1966). The Facit Dimension. London: Routledge and Kegan Paul.

46. Quinn, J.B., Anderson, P., \& Finkelstein, S. (1996). Making the mosh of the best, Harvard Business Review, 74(2):71-80.

47. Robertson, C.J. \& Crittenden, W.F. (2003). Mapping moral philosophies: strategic implications for multinational firms, Strategic Management Journal, 24:385-392.

48. Schroeder, R.G., Bates, K.A., \& Junttila, M.A. (2002). A resource-based view of manufacturing strategy and the relationship to manufacturing performance: Strategic Management Journal, 23:105-117.

49. Shamsie, J. (2003). The contex of dominance: An industry-driven framework for exploiting reputation, Strategic Management Journal, 24:199215.

50. Simon, D.G., Hitt, M.A., \& Ireland, R.D. (2007). Managing firm resources in dynamic markets to create value: Looking inside the black box. Academy of Management Review.

51. Snow, C.C. \& Hrebibak, E.G. (1980). Strategy, distinctive competence, and organizational performance, Administrative Science Quarterly, 25:317-336.

52. Song, M., Droge, C., Hanvanich, S. \& Calatone, R. (2005). Marketing and technology resource complementarily: An analysis of their interaction effect in two environmental contexts; Strategic Management Journal, 26, 259-276.

53. Subramani, M. \& Venkataraman, N. (2003). Safeguarding investments in a symmetric interorganizational relationships: Theory and evidence, Academy of Management Journal, 46:46-62.

54. Tallman, S., Jenkins, M., Henry, N., \& Pinch, S. (2004). Knowledge clusters and competitive advantage, Academy of Management Review, 29:258-271. 
55. West III, G.P. \& DeCastro, J. (2001). The achilles heel of firm strategic, resource weakness and distinctive inadequacies, Journal of Management Studies, 38: 417442.
56. Wheeleen, T.L; \& Hunger, J.D. (2004). Strategic Management and Business Policy, Upper Saddle River New Jersey: Pearson Education Inc. 